\title{
RÉPLICA VIRTUAL. Cámara obscura con diseño paramétrico y fabricación digital. Una arquitectura de la imagen virtual
}

\author{
VIRTUAL RÉPLICA. Camera Obscure With Parametric Design and Digital Fabrication. An \\ Architecture of the Virtual Image. \\ Nicolás Antonio Sáez Gutiérrez \\ Universidad del Bío Bío, Chile \\ nsaez@ubiobio.cl \\ Braulio Gatica Laurie \\ Singularity Sur, Laboratorio Cultural \\ brauliogatica@hotmail.com
}

\begin{abstract}
Virtual Replica is a contemporary artistic project that reflects upon our relation with the world. It is a camera (room) obscuradesigned with the aid of parametric software in order to be fabricated with CNC technology based on thin layers of plywood. An ephemeral architecture that creates an immersive experience for the visitor who is surrounded by a number of "virtual screens" exhibiting inverted images of the immediate exterior. This paper proposes the phenomenon of camera obscura as a proto building that gives life to an architecture of the image, using it as its built as well as its theoretical fundamental reference.
\end{abstract}

Keywords: Camera Oscura; Image Architecture; Parametric Design; Digital Fabrication; Contemporary Art.

\section{Introducción}

Réplica Virtual ${ }^{1}$ es un proyecto de arte contemporáneo que reflexiona sobre la relación virtual que tenemos entre nosotros y con el mundo. La instaurada predilección de la imagen, de la réplica, por sobre la experiencia directa con el original. Tal fenómeno social, simbolizado por las pantallas que cohabitan en nuestro cotidiano, tuvo un comienzo a partir de la instrumentalización de la "cámara obscura", primer mecanismo óptico - lumínico que dio paso a la primera "máquina para ver" y que a su vez dio origen a dicha relación virtual con el mundo. El fenómeno lumínico - óptico conocido como Cámara (habitación) Obscura, es un espectáculo mágico muy difícil de comprender sin previa experiencia. Este fenómeno ancestral dio origen a nuestra relación con la imagen "natural" del mundo, como réplica. Hoy no solo buscamos la réplica, sino que la consumimos, la producimos, la coleccionamos, la añoramos... la preferimos. Hoy la réplica ha reemplazado al original y pareciera que solo a través de ella podremos devolvernos otra vez al mundo de cuerpo entero.

El diseño y la fabricación digital del proyecto refuerzan la condición medial produciendo un objeto habitable con clara referencia al presente tecnológico. Se crea un interior hermético (cerrado al paso de la luz exterior) por una

1 Este trabajo de investigación arquitectónica-artística es parte de los resultados del grupo de investigación en Didáctica Proyectual de la Universidad del Bío Bío, Concepción - Chile. Cógido: Gl 160402/EF. envolvente compuesta por volúmenes poliédricos que actúan cada uno como cámaras obscuras. Cada volumen poliédrico es una caja de placa de madera hermética que tiene un estenopo óptico, conformado por un lente (lupa), mirando al exterior y un vidrio empavonado hacia el interior. La imagen virtual se proyecta nítida e invertida en la cara interior del vidrio empavonado que actúa como pantalla retro iluminada.

El diseño se basa en la geometría de un domo geodésico en frecuencia 2 dividido por malla dual en sesiones hexagonales y pentagonales, diseñado para ser fabricado digitalmente a partir de piezas poliédricas autosoportantes cuya una modulación esta armónicamente distribuida.

Réplica Virtual es un proyecto autoral de Nicolás Sáez ${ }^{2}$ y en proceso de co ejecución con "Singularity Sur, Laboratorio Cultural"3.

\section{Fotografía y Experiencia}

2 Desde el 2007 Nicolás Sáez se ha desarrollado autodidácticamente como Fotógrafo autoral. Su trabajo ha sido expuesto, premiado y publicado nacional e internacionalmente. Ver: www.nicolassaez.com

3 Singularity Sur Laboratorio Cultural, es una agrupación enfocada en el desarrollo del Arte Medial y Procesos Transdiciplinares. Su trabajo ha permitido transformarse en un actor mediador entre procesos curatoriales y técnicas de producción artística caracterizadas por ocupar la tecnología como motor en la fundamentación teórica, sobre todo al sur de Chile. 
"El acto fotográfico, un modo de certificar la experiencia, es también un modo de rechazarla: cuando se confina a la búsqueda de lo fotogénico, cuando se convierte la experiencia en una imagen, un recuerdo (souvenir)." (Sontag, 2006, p. 24).

La fotografía al igual que todo tipo de imagen es una reducción de la experiencia (SÁEZ, 2015). Abstraen un "algo" inserto en el mundo con sus cuatro dimensiones de espacio y tiempo a una superficie visual de dos dimensiones. Las imágenes median entre el hombre y el mundo. Ahora, la fotografía provocó un cambio trascendental con su aparición a mediados del siglo XIX precediendo a las imágenes tradicionales que poblaron por milenios nuestra historia a partir de la producción quirográfica (textos e imágenes manuales). La fotografía es producida por un "aparato" inventado a partir de una aplicación científica que conjuga problemas físicos de la luz, óptica, química (fotografía análoga) y ahora electrónica. Es una caja obscura programada para crear fotografías, y éstas en palabras de Flusser, inauguran la aparición de la imagen técnica (Flusser,1990, p.17). Así, el nivel de abstracción es mayor que con las imágenes tradicionales, ya que no solo reducen aquel "algo" inserto en el mundo si no que además lo hacen a partir de un invento científico programado para aquello. El operador-fotógrafo, si bien tiene la libertad de escoger lo que sea abstraer-fotografiar tiene que hacerlo según lo posible y programado por el aparato-cámara. Se suele pensar, erróneamente, que como la fotografía muestra una superficie visual "idéntica" a su referente, sumado a su condición "automática" en la obtención de dicha imagen, ella informa la "verdad" sobre lo capturado y se transforma en una evidencia de aquello. El realismo de la fotografía la sentenció, desde su invención, a ser "la constatación gráfica de la experiencia" a indicarla "como evidencia". Si bien históricamente nunca se cuestionó, salvo pequeñas excepciones, dicha natural acepción y su mayor utilidad radicaba en la misma, transformándola hasta nuestros días en un necesario recurso de verificación y respaldo a la hora de referenciar una información, es un hecho que desde su masificación y cambio tecnológico al formato digital, el operador-fotógrafo se ha trasformado en operador-fotógrafo-editor y su democratización instalada globalmente introdujo la "duda" a la experiencia de ver una fotografía. Hoy los niveles de alteración y manipulación digital de la imagen fotográfica han permitido desmitificar su "veracidad" introduciendo la lectura crítica a la apreciación de todos sus receptores. ¿Esto habrá sido? precede hoy al aporte Bartheiano del esto ha sido. (Barthes, 1982)

\section{Cámara (habitación) obscura, proto construcción de una arquitectura de la imagen}

"Se hace pasar la luz a través de un pequeño agujero hecho en un cuarto cerrado por todos sus lados. En la pared opuesta al agujero, se formará la imagen de lo que se encuentre enfrente" (Aristóteles. Siglo IV a.c.)
La historia de la cámara obscura, desde su descripción por Aristóteles hasta antes de la invención de la fotografía en el siglo XIX, ha pasado desde la pura contemplación del fenómeno a su instrumentalización útil para la profundización del conocimiento como mediador idóneo al momento de querer obtener una representación "fiel" del mundo.

Durante siglos, la cámara oscura fue utilizado sobre todo para observar los eclipses solares, ya que el ojo humano no puede tolerar la cantidad de luz que inunda cuando se mira directamente al sol. En tanto la filosofía platónica como para el cristianismo, bases del pensamiento occidental, la luz es símbolo de demiurgo y luego de dios. $Y$ si al mirar directamente a la luz enceguece, y dicha emanación proviene de un agente superior, el hecho de que un eclipse solar pudo ser visto de forma segura transformó a la cámara obscura en un refugio que recepciona las imágenes en su interior y son entendidas como una fuente confiable de información sobre lo que estaba ocurriendo en el mundo exterior. "Receiving surface" (Superficie receptora) (Silverman, 2015) es un concepto acuñado antes del Siglo XVIII y que describe la esencia de este rudimento arquitectónico anterior a la concepción "productiva" de la fotografía química. "When at the time of an eclipse of the sun, its rays are received in a dark place," (Cuando en el momento de un eclipse de sol, sus rayos se reciben en un lugar oscuro) Alhazen (965-1038), además aplicó el principio de la cámara oscura para explicar la formación de la imagen visual en el ojo.

Posteriormente se tiene una serie de proto científicos que aportaron a la utilidad de la cámara obscura mejorando la calidad de imagen proyectada y transmitiéndola como conocimiento a partir de tratados y descripciones detalladas. Roger Bacon (1214-1294), le incluye un espejo en 45 para proyecciones verticales; Gerolamo Cardano (1501-1576), un cristal biconvexo para lograr imágenes más brillantes y nítidas; Giambattista Della Porta (1535?-1605) la describe con mucha perfección y es el primero en recomendarla para la práctica del dibujo naturalista, y no solo para los artistas:

"Si no sabéis pintar, con este procedimiento podéis dibujar el contorno de las imágenes con un lápiz. Entonces no tenéis más que aplicar los colores. Esto se consigue proyectando la imagen sobre una mesa de dibujo con papel. Y para una persona que sea habilidosa la cosa resulta muy sencilla". (...) "Cualquiera, aunque ignore el arte del pintor, podrá dibujar la imagen de no importa qué objeto con un lápiz o una pluma". (Keim, 1971, p. 6)

Leonardo da Vinci (1452-1518) en sus escritos de inicios del s.XVI, 1515, acabó por consolidar la cámara oscura como instrumento de apoyo al dibujo naturalista describiendo el fenómeno con precisión a partir de la simple transformación de una habitación:

"Digo que si frente a un edificio o cualquier espacio abierto iluminado por el sol, tiene una vivienda frente al mismo y que si en la fachada que no enfrenta al sol se hace una abertura redonda y pequeña, todos los objetos iluminados proyectarán 
sus imágenes a través de ese orificio y serán visibles dentro de la vivienda sobre la pared opuesta, que deberá ser blanca, y allí estarán invertidos..." (Leonardo Da Vinci. 1515)

Ésta descripción precisa hecha por Leonardo del fenómeno de la cámara obscura, refiriéndose a "edificios iluminados" y una vivienda "receptora" de tal iluminación sin enfrentar la luz directa del sol, da cuenta de las condiciones lumínicas exteriores fundamentales necesarias para poder realizar el fenómeno, en una arquitectura existente.. y no necesariamente en la construcción de un aparato especifico. Leonardo habilitó un cuarto para experimentar la representación pictórica y estudiar la comprensión fisiológica del ojo humano. Es en el renacimiento dónde se consagró el arte pictórico naturalista que buscaba un realismo que intuía la visión fotográfica, muy distinto a lo hecho hasta ese momento sin un instrumento mediador. Los expertos coinciden que el uso de la cámara obscura en el desarrollo pictórico fue a partir del siglo XVII, analizando la obra de Vermeer y Canaletto. Sin embargo David Hockney`s en su libro "El conocimiento secreto" sostiene que ya en el siglo $\mathrm{XV}$, pintores occidentales ocuparon lentes y espejos, más las condiciones arquitectónicas entregadas por una habitación obscura para la ayuda del traspaso del dibujo naturalista. Según Hockney algo cambio en la manera de representar el mundo entre 1420 y 1430, un poco más de cuatro siglos antes de la aparición de la imagen técnica, de la fotografía química. El retrato del rostro, de interiores y exteriores de la ciudad, simboliza esta transformación en la comunicación de nuevas formas de ver el mundo.

Luego que Johannes Kepler (1571-1630) creara una cámara obscura tienda, que la hacía transportable y muy ligera para la ayuda del dibujo, Athanasius Kircher (1601-1680) jesuita y científico alemán, la perfecciona en su tratado Ars Magna Lucis et Umbrae (1646). Del grabado usado por Kircher (fig 00) se puede interpretar primero que por su condición transportable, la cámara obscura, se logra retratar a la ciudad desde lejos, transformándola en paisaje. Luego es la única representación de la época que ocupa varios estenopos (perforaciones), cada uno con un lente (cristal biconvexo) para lograr obtener varias proyecciones a las vez y dispuestas en el perímetro, proporcionado por una doble cámara, una opaca y otra translucida. El habitante entra por debajo de este aparato de tamaño de una habitación y queda aislado en este doble muro de separación. Desprendemos de esta interpretación la noción de "caverna platónica" en donde el habitante queda doblemente aislado para representar (comprender) su entorno inmediato, su mundo.

Si antes la cámara obscura mediaba para la comprensión de fenómenos en busca de verdades objetivas; luego usada para retratar personas, espacios y objetos mejorando dramáticamente el resultado naturalista; con Kircher comenzó una noción más amplia en torno a las posibilidades de representación, el muy interesado en todo lo exotérico y mágico, logra comprender lo atractivo que es para todo el mundo la producción de imágenes "fantasmales" terminando por desarrollar posteriormente su celebrado invento, la "Linterna Mágica". Las imágenes réplicas del mundo empiezan a generan gran interés y naturalmente lo que devino fue la fabricación de cámaras oscuras portátiles y cada vez de menor tamaño hasta llegar al descubrimiento de fijar químicamente dichas imágenes fantasmales.

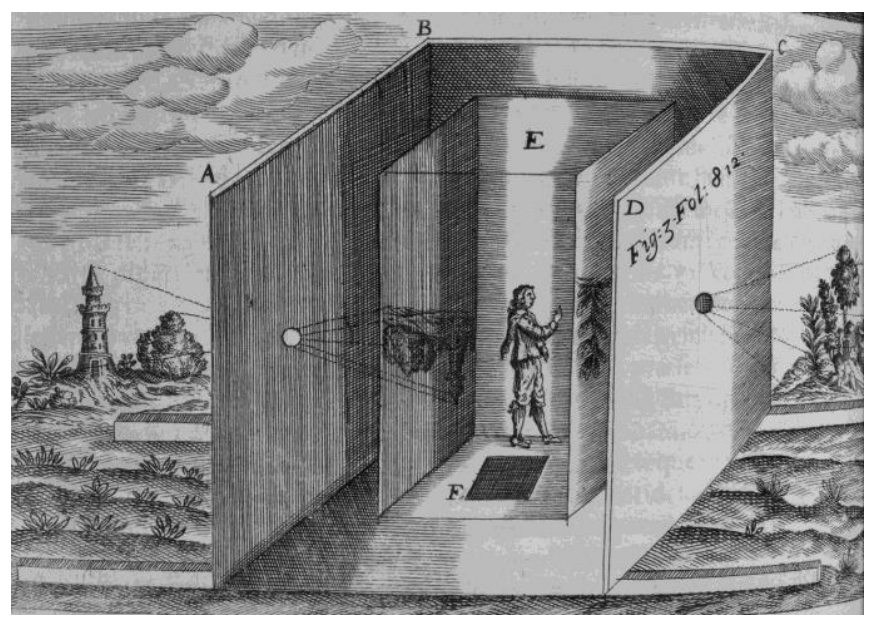

Figura 1: Cámara oscura descrita en Ars Magna Lvcis Et Vmbrae (1646). Athanasius Kircher (1601- 1680) La imagen se proyecta sobre una superficie traslúcida que permite al observador situarse al centro de la imagen para copiarla o analizarla sin estorbarse con su propia sombra.

\section{RÉPLICA VIRTUAL como arte contemporáneo}

La Cámara Obscura ha sobrevivido a nuestra actual era de la reproductividad de la imagen digital. Su carácter "mágico" sigue encantando sobre todo a artistas contemporáneos que ven precisamente el gran potencial que presenta desde lo analógico, desde lo pre fotográfico, en una era en donde la fotografía domina es un gran poder. Abelardo Morell, ha viajado por el mundo transformando habitaciones en cámaras obscuras. Luego registra fotográficamente el fenómeno logrando de forma inédita obtener la imagen doble: la de la habitación y la del espacio exterior proyectado lumínicamente dentro de ella. Pero no es precisamente un "documento" de tal experiencia, ya que sus fotografías dramatizan el efecto lumínico al ocupar obturaciones largas y una alta sensibilidad (ASA). La nitidez y gran iluminación del retrato se aleja de la experiencia a ojo desnudo al ser está mucho más leve... pero entendiendo que la fotografía es una reducción de la experiencia esta primera debe exagerar o mentir para acercarse a la verdad de la segunda (Fontcuberta, 2010). Existen cámaras obscuras habilitadas en edificios para el espectáculo y la recreación de visitantes que observan panorámicas a partir de esta experiencia interior. Además de referentes contemporáneos como la cámara oscura gigante, realizada por el fotógrafo Mariano Dallago, en la provincia italiana montañosa del Tirol del Sur; y el edificio Cámara Obscura erigida en la isla griega de Egina, como parte del proyecto cultural LUZ I IMAGEN I REALIDAD Europea - La Academia Egina 2003. En el diseño 
paramétrico tenemos como referente a ICD.ITKE Pabellón de
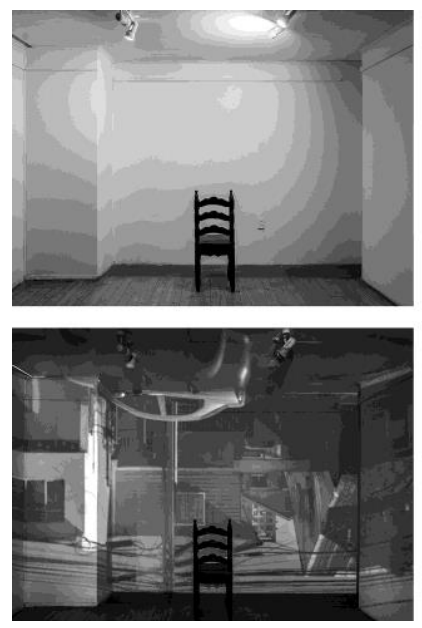

Investigación de la Universidad de Stuttgart.

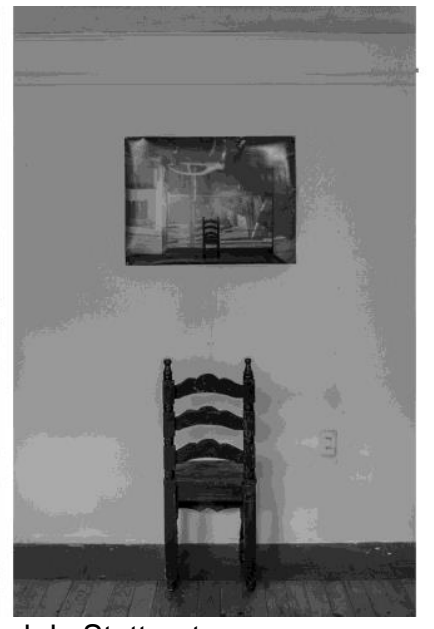

Figura 02: Ejemplo de cámara obscura de una habitación transformada y su réplica en una caja con lupa y vidrio empavonado. Proyecto "Réplica Obscura" de Nicolás Sáez en exposición colectiva "Frontera Invisible" de "Casa 916". Concepción - Chile, Agosto 2014. Registro: Casa 916. Fuente: Nicolás Sáez

\section{Proyecto, Diseño y Fabricación digital}

Réplica Virtual es un proyecto inédito en Chile que se concibe para provocar la reflexión al tener una experiencia con este tipo de Arquitectura de la Imagen virtual (Réplica). Cámara (habitación) Oscura diseñada paramétricamente en base a la estructura geométrica del Domo Geodésico y constituido por una serie de micro - cámaras (cajas) obscuras, de forma poliédrica (hexagonal y pentagonal) y autosoportantes. El domo tendrá $2,3 \mathrm{mts}$ de radio y un espesor (micro-cámara obscura) de 0,35 mts. Cada micro cámara (caja) Obscura se fabricará digitalmente para ser confeccionada a base de encaje a presión (borde endientado) con placa terciada de madera de $3 \mathrm{~mm}$ de espesor. Cada uno usará una lupa de $100 \mathrm{~mm}$ de diámetro y $2 x$ de aumento con un alcance focal de $30 \mathrm{~cm}$ aproximadamente. Existen un juego de enfoque entre lo mas cercano a lo lejano de $1 \mathrm{a} 2 \mathrm{~cm}$ de movimiento del lente en el eje de enfoque. Esto último obliga a colocar el lente dentro de un cilindro telescópico manual para enfocar las distintas vistas del lugar. El proyecto tendrá 91 piezas en total compuestas por 66 piezas-cámaras poliédricas hexagonales, 6 piezas-cámaras poliédricas pentagonales y 19 medias piezas poliédricas hexagonales que arman el anillo de base. Cada una de estás piezas pesarán menos de $5 \mathrm{~kg}$. las mayores y $3 \mathrm{~kg}$. las menores.

El proyecto podrá ser emplazado en cualquier lugar que cuente con un suelo plano y parejo. El acceso deberá estar orientado hacia el norte ya que la cámara obscura recibe por refracción la imagen exterior, por lo que la envolventecámara debe estar orientada preferentemente hacia el sur.

El interior de RÉPLICA VIRTUAL tendrá más de una proyección como imagen invertida permitiendo al visitante

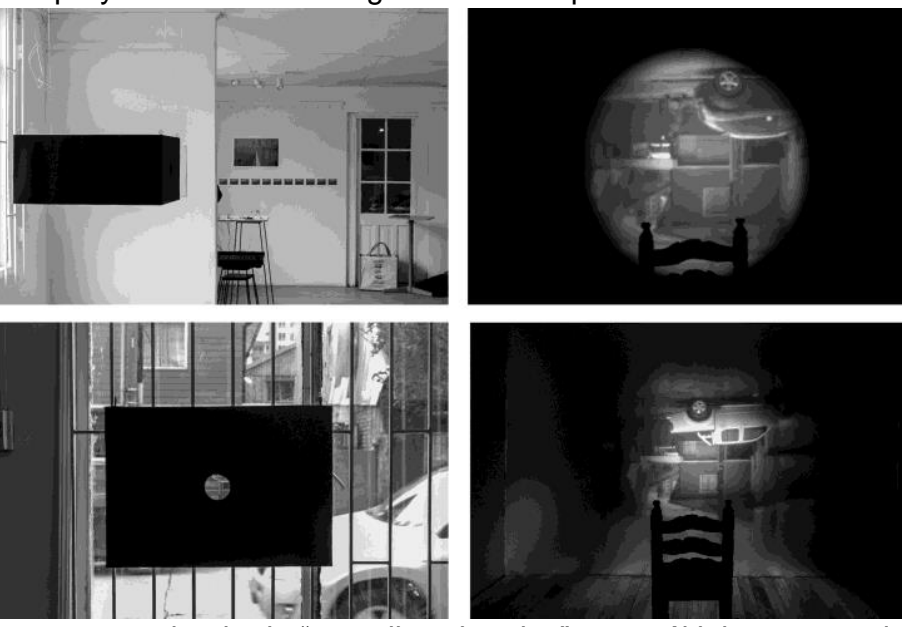

estar rodeado de "pantallas virtuales" con múltiples puntos de vista del entorno visual exterior. 



Figura 03: Vistas vectoriales y renders Réplica Virtual. Fuente: Singularity Sur.

\section{Metodología}

A continuación se presentará el desarrollo paso a paso del proyecto desde su modelación, parametrización, fabricación digital, ensamble modular y montaje.

1. Modelación 3D: El modelo se parametriza base a un icosaedro subdividido en segunda frecuencia, a su vez se divide en "malla dual" para generar la teselado hexagonal, bajo esta forma se dan las condiciones de trazado regulador en la cual se generan los volúmenes.

2. Ensamble paramétricos: El proceso de diseño digital, realizado en plataforma Rhinoceros y programado en Grasshopper con componentes nativos, fue diseñado para crear ensambles paramétricos y fabricación digital, mediante corte laser en terciado de $3 \mathrm{~mm}$.

3. Despiece y corte laser: La fabricación se modula en planchetas de $1.2 \times 1.2 \mathrm{~m}$, formato cortadora laser, sus ensambles se realizan por bordes endientados

4. Armado módulo: cada modulo se encola y ensambla con la facilidad que permiten los calces por fabricación digital. Luego se agregan los demás elementos para conformar el módulo - pieza cámara: Madera + Lente (lupa) + vidrio empavonado.

5. Embalaje y traslado: los módulos prefabricados al ser embalados para su traslado generan un volumen de $12 \mathrm{~m} 3$ y $4 \mathrm{~m} 3$ en su modalidad desarmados.

6. Montaje: Su montaje se realizará conformando anillos ascendentes y fijando cada pieza con tornillos. El acceso, definido por un vano, quedará cerrado a la luz exterior por una tela elasticada negra dividida al centro y tensada por un bastidor metálico, el cual quedará fijado a la estructura de madera modular por tornillos. Todo el proyecto podrá ser construido por una sola persona. 

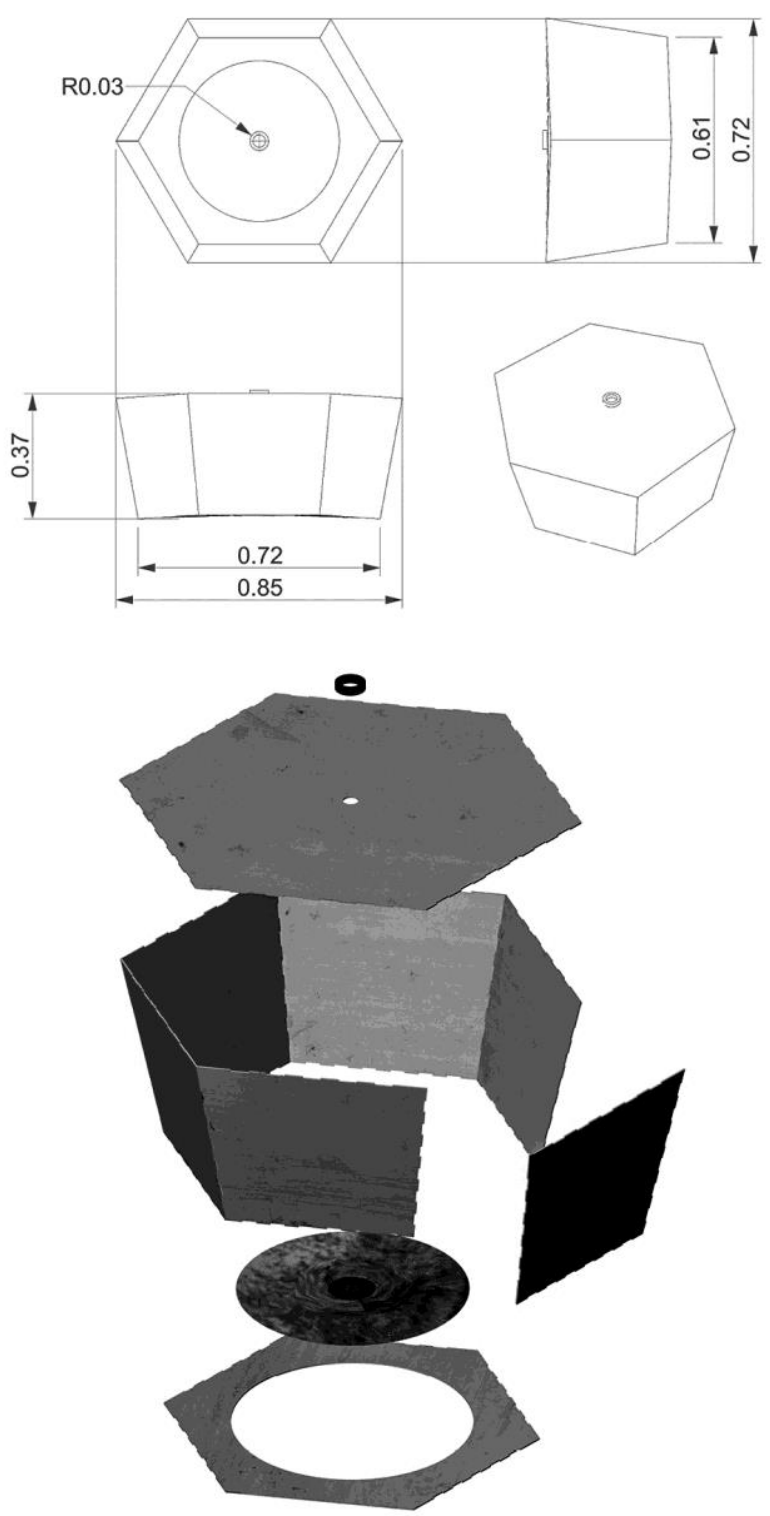

Figura 04: Vistas vectoriales pieza tipo y renders extruido en donde se aprecia ubicación de lente (lupa) y vidrio empavonado en el armado de un poliedro hexagonal. Fuente: Singularity Sur.
Figura 04: Fotomontaje de Réplica Virtual en dos posibles emplazamientos dentro del campus de la Universidad del Bío Bío, Concepción - Chile. Fuente: Nicolás Sáez.

\section{Conclusión}

Réplica virtual construye una experiencia inédita en el campo del arte fotográfico al ser un espacio que simula nuestra relación virtual con "pantallas" tecnológicas a partir del ancestral efecto lumínico de la cámara obscura. Al igual que en una cámara fotográfica el vidrio empavonado actuaria como el "visor digital", justo antes de tomar la fotografía. Dentro del objeto paramétrico quedamos completamente aislados del exterior e inmersos en la visión de cada imagen retroproyetada e invertida del exterior que acabamos de abandonar. Esta experiencia que incluye un efecto lumínico que no necesita electricidad, solo una buena orientación y un lindo día, pretende educar y presentar de forma didáctica lo que es nuestra relación con la imagen virtual en su condición alienante.

La obra propicia una experiencia individual mágica en donde, y a diferencia de nuestra actual relación con la imagen fotográfica, podemos por un lado comprender didácticamente el proceso que da origen a la fotografía y por otro comparar in situ, ambas visualidades... la de la experiencia directa a ojo desnudo con la que la representa al interior obscuro de una habitación... realidad versus magia.

En nuestra actual relación con la virtualidad, una invitación a realizar procesos contemplativos a ojo desnudo es claramente una nueva necesidad.

Con esto esperamos concretar la fabricación de Réplica Virtual entendido como un tipo de arquitectura de la imagen.
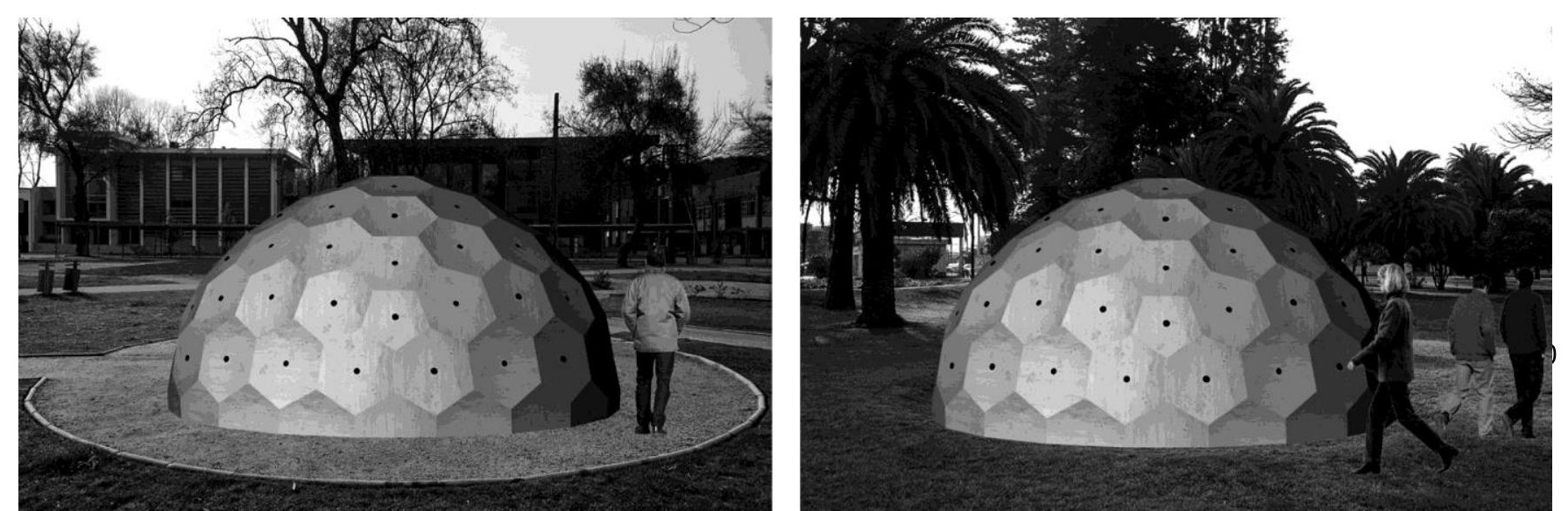
SIGraDi 2016, XX Congreso de la Sociedad Ibero-americana de Gráfica Digital

9-11, November, 2016 - Buenos Aires, Argentina

\section{Bibliografía}

\section{[Documentos]}

Sáez, Nicolás. 2015. "Voluntad Fotográfica. Hacia una intencionalidad en el uso de la fotografía en el campo educativo arquitectónico". Tesis Magíster Didáctica Proyectual UBB. Concepción - Chile.

\section{[Libros]}

Barthes, Roland. La Cámara Lúcida. Nota sobre Fotografía. [Libro]. - Barcelona, España. : Editorial Gustavo Gili, 1982.

Casa, Miguel. 2004. Magia y Ciencia: La invención de la Fotografía. Editorial Puerto de Palos. Santiago de Chile

Fontcuberta, Joan. 2010. La cámara de Pandora. La fotografí@ después de la fotografía. Barcelona: Editorial Gustavo Gili, SA.

Flusser, Vilém. 1990. Hacia una filosofía de la fotografía. México: Trillas: SIGMA (reimp,1998)

Keim, Jean A. (1971) Historia de la Fotografía, Ed. OikosTau, Barcelona.

Sontag, Susan. Sobre la Fotografía. Buenas Aires, Argentina : Aguilar, Altea, Taurus, Alfaguara, 2006.

\section{[artículos]}

Sáez, Nicolás; Alvarado, Rodrigo García; Costa, Matthias Dalla; Chiarella, Mauro; Gronda, Luciana; Lara, Luis García; Veizaga, Martin; "BANCAPAR. Paramétrico objeto de arte público con Diseño de fabricación y de colaboración en los países industrializados", p. 527-531. En: Actas de la XVIII Conferencia de la Sociedad Iberoamericana de Gráfica Digital: Diseño en libertad [= Blucher Diseño Proceedings, versión 1, n.8] . Sao Paulo: Blucher, 2014. ISSN 2.318 a 6.968, DOI 10.5151 / despro-sigradi2014-0109

Sáez, Nicolás. Ejercicio de arte fotográfico. Reconstrucción de una vivencia espacial a través de una percepción inmersiva de la imagen (Fotografía) - escena (Arquitectura). SIGraDi 2012 [Proceedings of the 16th Iberoamerican Congress of Digital Graphics] Brasil - Fortaleza 2012, pp. 373-377. Revisar en: http://papers.cumincad.org/data/works/att/sigradi2012 167.c ontent.pdf

Sáez, Nicolás. Ejercicios de arte fotográfico, desde una perspectiva arquitectónica: una ecología de la imagen digital. Congreso SIGRADI 2011. [Proceedings of the 15th Iberoamerican Congress of Digital Graphics] Santa Fé, Argentina. http://cumincades.scix.net/data/works/att/sigradi2011 346.co ntent.pdf

\section{[En línea]}

SILVERMAN, Kaja. (2015) The Miracle of Analogy: or The History of Photography, Part 1. Stanford University Press. Revisar en: https://monoskop.org/media/text/silverman 2015 history of photography $1 /$ 